\title{
The Equal Earth Projection: Distortion Characteristics, Adoption, and (Social) Media Impact
}

\author{
Bojan Šavrič ${ }^{\mathrm{a}}{ }^{*}$, Bernhard Jenny $^{\mathrm{b}}$, Tom Patterson $^{\mathrm{c}}$ \\ ${ }^{a}$ Esri, Inc., Redlands, California,USA, BSavric@esri.com \\ ${ }^{b}$ Faculty of Information Technology, Monash University, Melbourne, Australia, Bernie.Jenny@monash.edu \\ ${ }^{c}$ U.S. National Park Service (ret.), Harpers Ferry, West Virginia, USA, mtnmapper@gmail.com \\ * Corresponding author
}

Keywords: Equal Earth, world map, pseudocylindrical, Robinson, Gall-Peters, media coverage, social media

\begin{abstract}
:
The Equal Earth map projection (Figure 1) is a new pseudocylindrical projection for world maps. It is similar to the popular Robinson projection, but unlike the Robinson, it is an equal-area projection. The projection shows continental outlines in a visually pleasing and balanced way. Its equations are simple to implement and fast to evaluate. The creation of this projection was motivated by a wave of news stories about Boston Public Schools switching to maps using the Peters projection. Since its online publication in August 2018, the projection has already been adopted in various software and projection libraries and it has been featured by media outlets around the world.
\end{abstract}

This presentation will show the distortion characteristics of Equal Earth and compare them to the Robinson projection as well as a few other well-known equal-area projections. We will cover some of the published world maps that use Equal Earth and list the software that has adopted the projection. Finally, media reporting and the impact of rapid popularity via social media circulation will be discussed.

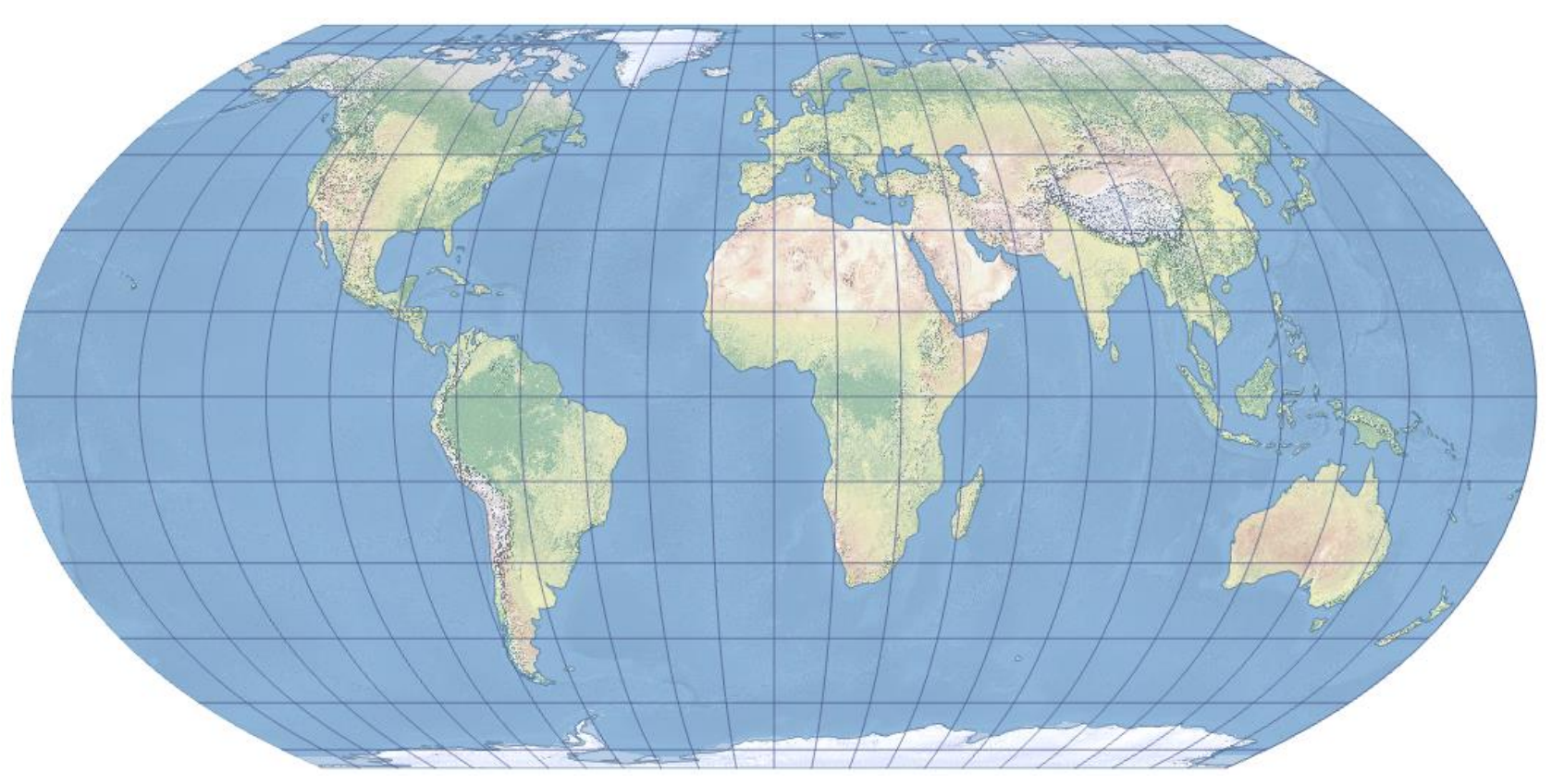

Figure 1. Equal Earth map projection. 